Please do not remove this page

RMIT

UNIVERSITY

\title{
Materialising energy and water resources in everyday practices: Insights for securing supply systems
}

Strengers, Yolande; Maller, Cecily

https://researchrepository.rmit.edu.au/esploro/outputs/9921858790401341/filesAndLinks?institution=61RMIT_INST\&index=null

Strengers, Y., \& Maller, C. (2012). Materialising energy and water resources in everyday practices: Insights for securing supply systems. Global Environmental Change, 22(3), 754-763.

https://doi.org/10.1016/j.gloenvcha.2012.04.004

Document Version: Accepted Manuscript

Published Version: https://doi.org/10.1016/j.gloenvcha.2012.04.004

Repository homepage: https://researchrepository.rmit.edu.au

(C) 2012 Elsevier

Downloaded On 2023/04/26 13:47:17 +1000

Please do not remove this page 
Thank you for downloading this document from the RMIT Research Repository.

The RMIT Research Repository is an open access database showcasing the research outputs of RMIT University researchers.

RMIT Research Repository:http://researchbank.rmit.edu.au/

\section{Citation:}

Strengers, Y and Maller, C 2012, 'Materialising energy and water resources in everyday practices: Insights for securing supply systems', Global Environmental Change, vol. 22, no. 3, pp. 754-763.

See this record in the RMIT Research Repository at:

http://researchbank.rmit.edu.au/view/rmit:17990

Version: Accepted Manuscript

Copyright Statement: (C) 2012 Elsevier

Link to Published Version:

http://dx.doi.org/10.1016/j.gloenvcha.2012.04.004 


\title{
Materialising energy and water resources in everyday practices: insights for securing supply systems
}

\begin{abstract}
Policies to secure energy and water supplies from the impacts of climate change are currently being developed or are in place in many developed nations. Little is known about how these policies of security, and the systems of resource provision they prioritise, affect householders' capacity to adapt to climate change. To better understand the connections between resource provision and consumption, this paper explores the notion that different 'energies' and 'waters' can be conceptualised as material elements of social practices, which shape the way practices are performed. We draw on a study of Australian migrants and their experiences with different resource provision systems in multiple countries, time periods and contexts across three generations. We discuss the differing characteristics of energy and water provision across three broad resource 'eras', and the way resources enable or reduce resourcefulness, adaptive capacity and resilience. We find that policy makers may inadvertently reduce householders' capacity to respond and adapt to climate change impacts by prioritising the resource characteristics of immateriality, abundance and homogeneity. We conclude that policy which prioritises the resource characteristics of materiality, diversity and scarcity is an important, underutilised and currently unacknowledged source of adaptive capacity.
\end{abstract}

Keywords: climate change adaptation, migration, social practices, materiality, consumption, security 


\section{Introduction}

Climate change adaptation policy is underpinned by a discourse of 'securing supply' that promotes large-scale, centrally-managed supply systems designed to shelter households from the effects of climate change. The promise of supply security raises a number of unexplored questions, such as whether this policy response will involve new path dependencies that 'lock-in' (Arthur 1989) the maladaptive and resource-intensive practices they support; how this discourse of supply security corresponds with that of personal accountability for consumption and climate change (Hobson 2004); and whether securing supply systems is even possible, given the dynamic interplay between supply and demand (Van Vliet et al. 2005).

There are many useful places to begin in addressing these policy gaps, not least a history of scholarship exploring the ways in which large technical systems shape the way we live (Bijker et al. 1987; Hughes 1983; MacKenzie \& Wajcman 1999; Summerton 1994; Winner 1986). In his landmark historical analysis of the electricity supply system, Networks of Power, Thomas Hughes (1983, p. 2) begins with the deceptively simple insight that 'electric power systems, like so much other technology, are both the causes and effects of social change'. More recently, sociotechnical researchers have demonstrated links between energy and water infrastructure provision and changes in demand (Chappells \& Shove 2004; Strengers 2011; Van Vliet et al. 2005; Woodruff et al. 2008).

Cultural studies of household water practices also highlight connections between the provision of resources and householders' capacity to adapt to resource shortages during drought. In their study of changing water cultures in Eastern Australian backyards, Head and Muir (2007, p. 898) link water-saving practices and 'the normality of scarcity' to 'rural or agricultural childhoods and living with tank water'. Similar findings are reported by Allon and Sofoulis (2006, p. 50) in their study of cultural water practices in Sydney, where they suggest 'that exposure to different "regimes of water" gives people the imaginative capacity to adopt a different approach to using water'. Despite these accounts, the role that resources and their infrastructures play in constituting everyday 
practices is under-developed. While there is a clear link between demand and supply, we are yet to fully understand the complexity of this relationship.

Theories of social practice provide a fruitful avenue for addressing these issues, because they focus attention on assemblages of human and non-human actors that are 'always on the move' (Shove et al. 2007, p. 8). Rather than viewing technologies and objects as historical actors that determine the future, or passive devices that are manipulated by social forces, some social practice theorists position them as 'necessary, irreplaceable components of certain social practices' (Reckwitz 2002a, p. 210). Supply and demand are no longer viewed as separate and separable categories, but are instead viewed as a suite of intimately interwoven practices, whereby the technologies of resource provision (taps, sockets, pipes and wires) interact with the ways resources are consumed and used in the course of everyday life. In this sense, the social significance of energy and water systems 'does not only consist in their being "interpreted" in certain ways, but also in their being "handled" in certain ways' through their integration and enactment in practice (Reckwitz 2002a, p. 210). We adopt this theoretical perspective to explore specific characteristics of energy and water systems, and the ways in which these resources intersect with, and manifest themselves, within everyday practices. Our aim is to discern whether conceptualising resources as materials in the constitution of social practices, provides insight into the ways in which systems of resource provision contribute to householders' ability to adapt to climate change.

To undertake this task, we draw on a study of Australian migrants living in Sydney and Melbourne, which investigated their experiences with different resource provision systems in multiple countries, time periods and contexts (Maller 2011). We identify three broad resource 'eras' with specific characteristics that give energy and water differing and multiple properties as a material element of household practices. Our analysis implies that policy makers may inadvertently reduce householders' adaptive capacity to respond to climate change impacts by pursuing policies of resource security, which prioritise the construction of large scale, remote systems of energy and water provision. Instead we argue that climate change adaptation policy, which promotes systems (and resources) 
which exhibit characteristics of materiality, diversity and scarcity, may foster and support adaptive capacity. By materiality we mean the proximity and visibility of resource systems in everyday life (e.g. their material presence); diversity refers to the range or variety of resource systems available, and; scarcity to their relative availability or perceptions of their availability. We conclude that access to material, diverse and scarce resources may increase householders' ability to adapt to climate change, and build household and community resilience to fluctuations in resource availability, which are predicted to increase under scenarios of climate change (IPCC 2007).

\section{Securing resources: illusions and fantasies of supply}

After several decades of conservation and demand-side interventions, many of which are still continuing, the 'secure and supply' discourse permeating resource management in many modern nations represents a return to nation-state (or in some cases private) management and control remnant of the 'predict and provide' period of modernity (Guy \& Marvin 2001). It also points toward an attempt to avoid or reduce the predicted impacts of climate change, irrespective of how people actually use resources such as energy and water. While this discourse has emerged in response to a complicated set of arrangements which differ within and between countries, the expected impacts of climate change have played a significant role in its creation and increasing popularity.

In Australia, a string of policies and reports on energy and water supply security have emerged including: Securing Australia's Energy Future (CoA 2004), Securing a Clean Energy Future (CoA 2011), and the National Energy Security Assessment (DRET 2009). These and other documents promise to provide 'adequate, reliable and affordable energy to meet future energy needs' (DRET 2011) and “[secure] ... longterm water supplies” (Wong 2009) “drop by drop” (DSEWPC 2011). Similar titles can be found in Europe and the UK, such as A European Strategy for Sustainable, Competitive and Secure Energy (CEC 2006) and Energy Security (Winstone et al. 2007). In these examples, governments are concerned with protecting consumers from 
climate change and its impacts (amongst other security challenges), while maintaining (and improving) consumers' access to energy and water supplies.

There are several problematic illusions reinforced in policies of securing supply. Firstly, they are conceptually and practically disconnected from a suite of policies concerned with individual accountability for climate change. Popular book titles, such as Greeniology (Ha 2007), Easy Green Living (Loux 2008) and It's Easy Being Green (Trask 2006), promise to support individuals to become eco-citizens, as do many behaviour change and demand management policies and programs. The illusion here is an artificial separation between supply and demand. Supply is something to be secured and protected for and from consumers; yet at the same time consumers are directly and personally responsible for their demand and its impacts. Such stark divisions obscure possibilities to explore connections between resource provision and consumption, and undermine integrated policy (Southerton et al. 2004; Van Vliet et al. 2005). More worryingly, this divide creates the perception that the links between supply and demand do not exist.

A second illusion embedded in this policy response is that nations can secure themselves not only from physical climatic changes, but from changes in the way we live. Suggesting that resources can be secured ignores the natural, social and institutional phenomenon which they both shape and are shaped by (Hughes 1983). As Dourish and Bell (2011, pp. 28-9) suggest, the notion that infrastructures can be treated this way is implausible:

thinking of infrastructure as stable, uniform, seamless, and universally available is clearly problematic. It is not merely a dream of a world not yet realized; it is a dream of a world that could never be realized.

Finally, the notion that energy and water systems can be rationally, instrumentally and discretely managed, irrespective of their relation with the world and people who use them, is equally problematic. As Star points out, 'nobody is really in charge of infrastructure', because it 'is big, layered, and complex, and because it means different 
things locally' (Star 1999, p. 382). These illusions create problematic gaps between supply and demand, generate fantasies of supply and security, and reinforce a fanciful notion that infrastructures can be controlled and managed by one set of actors.

The Australian Government's recent interest in desalination as a policy response to the nation's drought illustrates all three points. Desalination promises security and constancy of supply, irrespective of water shortages. However, desalination reduces householders' need to use water resources conservatively, and potentially introduces new dependencies and expectations that increase the demand for this energy-intensive resource supply (Barnett \& O'Neill 2009; Spearritt 2008). Like any large-scale system, desalination is not immune to breakdowns and collapses, nor is it invulnerable to supply shortages; in fact, it may create them. In promising secure supply, such systems potentially herald the return of old (and new) water-consuming practices designed to make use of this abundant resource, along with the potential loss of householders' resourcefulness and adaptive capacity developed during a decade of drought.

In seeking a more nuanced understanding of the implications of securing supply on householders' ability to adapt to climate change, we turn our attention to theories of social practice - an area of enquiry that Shove (2010, p. 283) describes as 'positively fizzing with potential'. As it is central to our main argument, we hone in on the notion of materiality as conceptualised in theories of social practice.

\section{Materiality in theories of social practice}

The observation that material things co-constitute the social world is not new. Latour $(1987,2000)$ has consistently called for material artifacts (non-human actors) to be understood as having the same status and agency as human actors in understandings and accounts of social order:

They [material artefacts] are not 'reflecting' it, as if the 'reflected' society existed somewhere else and was made of some other stuff. They are in 
large part the stuff out of which socialness is made (Latour 2000, pp. 1134).

Latour's view of material objects is foundational to science and technology studies, where 'more-than-human or hybrid dynamics of meaning and matter are central' (Hawkins \& Race 2011, p. 114).

Shove and her colleagues (Shove et al. 2007, p. 13), while sympathetic to the Latourian premise, argue that the "contention that artefacts construct socialness has yet to be worked through in any detail'. In attempting to tease out the role stuff plays in 'the development, persistence and disappearance of patterns ... of everyday life' (Shove et al. 2007, p. 3), they draw on theories of social practice, particularly the work of Schatzki (2002) and Reckwitz (2002a, 2002b). Here material objects, including technologies, infrastructures and artefacts, become active participants in social practices:

These things are 'interpreted' by the human agents in certain ways, but at the same time they are applied, used, and must be handled within their materiality (Reckwitz 2002a, p. 208).

As an important side note, the inclusion of materials as 'non-human actors' or as an element of social practices has emerged from a 'posthumanist' minority centered in Science and Technology Studies (Schatzki 2001). Not all social practice theorists attribute this role and agency to materials; some viewing them as 'mediators' of social practices, rather than active 'ingredients' of them. This material strand of social practice theory thereby accounts for technologies and infrastructures as an element of recognisable practice entities, such as cycling, laundering or cooking (Schatzki 2002). For instance, you cannot cycle without a bicycle. By definition the material element of a practice intersects with others, such as practical knowledge about how to perform a practice; and common understandings about what one ought to do and why (Pantzar \& Shove 2010; Strengers \& Maller 2011). Simultaneously, theories of practice focus attention on the performative nature of practices, and the role materials and other 
elements play in transforming or potentially fixing a practice in place \{Pantzar, 2010 \#839\}.

Taken together, Schatzki (2001, p. 3) suggests that this theoretical position 'promulgate(s) a distinct social ontology' whereby 'the social is a field of embodied, materially interwoven practices centrally organized around shared practical understandings'. Theories of practice thereby account for the role of material objects in contributing to both obduracy and change, not by reflecting changes in society or by acting upon it, but through their role in the constitution and performance of everyday practices.

However, most materially-oriented practice accounts have focused on the role of discrete objects, artefacts and technologies in constituting social practices. For example, airconditioners are central to changing cooling practices (Strengers 2010; Strengers \& Maller 2011), cameras to photography (Shove et al. 2007), bottles to drinking bottled water (Hawkins \& Race 2011), hardware to do-it-yourself renovations (Shove et al. 2007), and walking sticks to the practice of Nordic walking (Pantzar \& Shove 2010). In these accounts, discrete objects and things are counted as elements with their own 'histories and futures', which are 'routinely transformed by and through specific integrations in practice' (Pantzar \& Shove 2010, p. 450). While systems of resource provision are alluded to, they lack clear roles as discernable material 'things' in the constitution of practices.

In some socio-technical accounts, systems of provision are afforded greater agency and material status in practices through their role in 'scripting' (Akrich 1992) and mediating appliances and technologies - these being the 'sensitive fingertips' (Shove \& Chappells 2001) or 'terminals' (Otnes 1988) of larger infrastructural systems and arrangements (Southerton et al. 2004; Van Vliet et al. 2005). For example, in Sofoulis' (2005) account of domestic water consumption, showers and washing machines are positioned as legacies of large-scale systems which encourage householders to engage in wasteful water practices, rather than saving and reclaiming water as recommended in conservation 
campaigns. Similarly, Chappells \& Shove (2004, p. 132) discuss the mediating role played by 'complexes of material stuff', which are 'channeled, contained and collected through a network of aqueducts, pipes, taps and sinks'. Infrastructures such as pipes and power lines are described as 'connective tissue' that bind and lock providers and consumers into 'distinctive regimes of resource management' (Chappells \& Shove 2004, p. 142).

These accounts provide insight into the links between production and consumption that should raise concern for any policy maker pursing large-scale infrastructural investments in the interests of securing supply, as well as clues on what alternative types of infrastructural arrangements might enhance householders' adaptive capacity. However, theoretically we are still left with questions about how resources can be accounted for in theories of practice. Are they only relevant in relation to the 'sensitive fingertips' of the home (e.g. appliances that need resources to operate) or can they be thought of as material elements in their own right? If so, how can we make links between the characteristics of energy and water systems and the everyday practices people perform? Drawing on a study of migrant households who have experienced dramatic changes in their access to energy and water systems during their lifetimes, we explore these lines of enquiry.

\section{Migrant households and resource eras}

Migrants to Australia represent a rich site of enquiry for understanding how changing systems of energy and water provision co-constitute household practices. In this paper we draw on interview data from nineteen migrant households (37 individual participants) from Italian, Greek, Maltese, Vietnamese, Chinese, Indian and Sri Lankan backgrounds living in the cities of Melbourne and Sydney (Maller 2011). These householders migrated from European and south-east Asian countries with tropical, dry Summer, sub-tropical or Mediterranean climates (based on the Köppen-Geiger climate classification system (Peel et al. 2007)). All households had lived in Australia for more than 20 years, with some having settled more than 50 years ago. 
Interviews were conducted with multiple generations of migrants from the same household (most with two generations per household). Participants were asked to describe the energy and water systems they had access to in their home countries as well as those they had encountered since moving to Australia, and the ways in which these were involved in the coordination and enactment of daily practices. The interview covered a range of household practices, including heating and cooling, cooking, cleaning, laundering and bathing. As part of the interview, householders were asked to undertake a 'walk through' tour focusing on everyday activities (Strengers 2009). Interviews were voice-recorded, transcribed and coded using qualitative analysis software. Names have been changed to protect the identity of participants.

We discern from the data three distinguishable eras of resource provision characterising household practices. Eras refer broadly to particular time periods and places; they are not intended to be discrete, hence there is a small degree of overlap. Labelled according to their main characteristics, they are:

- Era 1: materiality, scarcity and diversity, referring to the 1950-70s in migrants' countries of origin;

- Era 2: immateriality, abundance and homogeneity, referring to the 1970-90s in Australia, and;

- Era 3: Re-materiality, scarcity and diversity through innovation, referring to the 1990-2010s in Australia.

Era 1 bundles together a wide variety of energy and water arrangements in both city and rural contexts in migrants' home countries. These were characterised by regular intermittency and disruption of centrally managed systems, minimal treatment and disposal infrastructure, scarcity, and elaborate collection techniques for multiple energy and water sources. This era includes considerable personal hardship experienced by some migrant households during confinement in refugee camps in South-East Asia, as well as the relative abundance and wealth experienced by others, 
some who hired maids or had other helpers to undertake many daily practices on which energy and water depended (cooking, laundering etc.)

Era 2 refers to the abundant, cheap and available water and energy sources accessed by migrants on their arrival to Australia resulting from the 'build and supply' period of modernity (Guy \& Marvin 1996, 2001). The creation, storage and delivery of resources were largely hidden or obscured from view, rendering them immaterial in householders' everyday lives. Resources arrived to the home through taps and electricity sockets that made different sources of energy and water indistinguishable from one another. Era 3 characterises the recent decline in energy and water availability and affordability as a result of resource issues in Australia and internationally, such as drought, peak electricity demand, and climate change, which have partially repositioned water and energy as scarce and valuable resources. These resources have gained visibility in everyday life as householders attempt to save, collect, store and reuse them in inventive ways. However, Era 3 also refers to current tensions with Era 2 as governments attempt to re-secure supply. In the sections that follow, we elaborate on the resource characteristics of these eras, the role of resources as a material element of everyday domestic practices, and the corresponding adaptiveness of migrant householders’ practices to changing resource conditions.

\section{Era 1: Materiality, scarcity and diversity}

First generation migrants to developed nations in the 1950-1970s generally came from 'unsophisticated' systems of energy and water provision. By this we mean that energy and water systems were usually localised, low-tech and highly dependent on physical human labour. The village well is a classic example. Despite significant variations in the provision of energy and water during this era, three characteristics of such systems are identifiable in the data: (i) proximal materiality, meaning energy and water supply systems are physically present in the immediate surrounds of those using them and require active engagement from their users; (ii) diversity, involving the use of multiple 'energies' and 'waters' from varying sources with different qualities and characteristics; and (iii) scarcity, resulting from heightened vulnerability to climatic variation and/or 
frequent disruption due to limited capacity, population pressure or overstretched distribution networks. The following discussion elaborates on how these characteristics informed the practices performed by migrant households.

The proximal materiality of the systems migrants grew up with required engagement with raw materials (e.g. wood, river water), their transport to the home, and their transformation into useful or usable energy and water sources (e.g. boiled water). This involved a set of resource-making practices, requiring materials such as buckets, axes and donkeys; practical knowledge about how and what to collect; and common understandings about how it should be treated and for what purpose. For example, householders recounted stories of filtering or boiling rainwater or tap water before it was ready for cooking or drinking. Clay vessels were often used to store treated water in humid climates because they kept the water clean and cool. Sanjeev, a Sri Lankan firstgeneration migrant, described the practices involved in collecting, treating or storing usable water:

That device is an earthenware water container, so what you do each morning the water boils and boiling water is put into that to cool, because it's a porous thing it loses heat quite quickly and it gets quite cool and people drink out of that. So the top was also made out of earthenware and it doubles as a cup as well as the top, so the loss of heat from outside keeps it cool ... Because you lose a lot of water due to the humidity you drink a lot of water (Sanjeev).

Importantly, different energies and waters were made and used for different tasks. In this sense, resources were characterised by diversification: some energies and waters had their own set of practices involved in making, treating and sorting them into usable forms, and each was designated for use in specific practices, such as drinking, bathing, heating or cooking. For example, Marco, discussing the experiences of his first generation Italian migrant parents, described how 'pure' water for drinking and cooking was sourced from natural mountain springs; water for washing clothes and linen came from a river; and 
heavily chlorinated piped water was used for washing dishes and the body. Similarly, grid-connected electricity enabled lighting at night, while gas, wood or kerosene were used for cooking because electricity was expensive, unavailable or limited, and/or because few households had an electric stove.

Scarcity was another key characteristic of this era, manifesting itself through intermittent or disrupted supply. Households often experienced energy and water disruption in the form of rolling blackouts, restricted supply (imposed by utilities or governments), or drought.

The electricity always off. Like, maybe you're off for 1 or 2 day... maybe in the morning you don't have or at 9:00, maybe they cut off the electric for a few hours. So you don't have 24-hour electricity (Nicole).

Scarcity was further enhanced through the proximal materiality and diversity of resources discussed above (e.g. due to the hard work required to make, collect and store energies and waters), and was manifested in householders' practices through the common understanding of not wasting. The scarcity of resources encouraged resourcefulness: it gave energy and water (and other resources such as food) the status of valuable materials; things to be used carefully and conservatively:

Everything was [used], you couldn't waste it. And that's why it's still in me (Dhara).

If you've got something you've got to make the most of it, stretch it as much as you can so ... you don't waste (Jim).

The data also suggest that disruptions to energy and water supply were viewed as a normal and largely accepted part of everyday life: 
There was power cutting out sometimes ... so then you had to, you know, wait till it comes on ... most of the time we had the gas cooking ... So it wasn't bad ... As far as I can remember I didn't suffer (Shanthi).

One reason why interrupted supply was not reported to have a great impact on households may be because domestic technologies such as washing machines and other modern appliances were rare, if not entirely absent. The independence from household appliances dependent on centrally-controlled systems enabled flexible routines that could be shaped around the disruptions households encountered. However, householders' acceptance of disruption was not just a product of their relative independence from piped and grid-connected systems. Rather, disruptions were ‘constitutive features of lived normality' (Trentmann 2009 p. 94), around which practices and routines were developed and scheduled in accordance with availability.

For example, in Dhara's household in India, where the water supply was only available in the morning, daily routines were adapted around this resource's availability. Practices incorporating piped water were performed at particular junctures in the day, or water was collected and stored (giving it proximal materiality) for use at other times:

...we used to have water only until 10:00 or 11:00am in the morning for the whole day. We had tanks, and [they] would fill up, and that was it. We'd have our showers during that time, or whatever, and then we used water sparingly. Even though the servants came in later and did the washing up...they did it from buckets (Dhara).

Like other material objects, resources in this era were experienced essential components of certain social practices that required specific handling and knowing (Reckwitz 2002a). The characteristics of proximal materiality, diversity and scarcity, gave resources the status of material things in the practices they were subsequently used for (Reckwitz 
2002a). Rather than being passive bystanders in practices, energies and waters were active elements-something on which routines were enacted, competencies created (about how to be resourceful), and common understandings formed (such as not wasting).

\section{Era 2: Immateriality, abundance and homogeneity}

When these migrants arrived in Australia their access to resources changed dramatically, as did the characteristics of the resources they used. Instead of material, scarce and diverse energies and waters, householders had access to immaterial, abundant and homogeneous energy and water systems. This era roughly corresponds with the period 1970-90s, when Australia had realised its dream of providing safe and abundant energy and water supply to the masses, despite emerging challenges such as drought (Davidson 2008). In contrast to the proximal materiality of energy and water resources in Era 1, their immateriality in Era 2 refers to their hidden and inconspicuous nature, and their receding visibility in everyday life. Reliable and large-scale dams and electricity systems located 'out of sight, out of mind' reinforced the illusion that energy and water was always available. For most of the population, water came from a tap and energy from a socket or gas pipe, regardless of where it came from or how it was produced.

Given the significant differences in energy and water provision during this era, as well as major changes to other elements of practices, we might assume that migrants' practices changed radically on arrival to Australia. However, Nicole, a Vietnamese first-generation migrant of Chinese descent, demonstrates that this is not necessarily the case. Nicole had spent years drifting between different rental houses when she arrived in Australia as a refugee, being exposed to many different and new practices as she settled into a new country. During this period, she continued to use water resources conservatively. Even in Era 3, when Nicole was prepared to use the dishwasher, she used 'low flow' settings and described her new dishwashing practice as the 'lazy' way of doing things. Similarly, the clothes dryer was reserved for an 'emergency or when it a rainy day'. New appliances were used tentatively, cautiously and frugally. Nicole's common understanding of not wasting, which emerged from years of living with material, scarce and diverse energy 
and water sources described in Era 1, remained intact in many practices throughout eras 2 and 3, despite dramatic changes in resource provision and availability.

While there was different practical knowledge regarding how this understanding should be manifested in practice (e.g. how one should go about reducing waste), this understanding was embodied in nearly all of the migrants’ practices. For example, Marco and Tessa, second generation Italian migrants, described how they saved water and energy in Australia at every possible turn because ‘that's how I was brought up’ and because 'there was never taking anything for granted'. Dhara describes the embodiment of not wasting as a type of routine in its own right: a form of 'saving' that 'automatically comes' in all of her practices involving resources, which is reflected in her comment: 'I brought India here’.

Although affordability may offer some explanation for migrants' continuing to focus on energy and water savings, data from this era indicate that the average energy bill was low, representing between 1.7-2.7 per cent of household average weekly earnings (AEMC 2011, p. 12). The cost of water to households during this time was so marginal, it was not listed as a separate item in the Australian Bureau of Statistics (ABS 2011) household expenditure surveys, instead being bundled in with rates and home maintenance costs. Furthermore, for households renting apartments or other detached dwellings, water expenses were often borne solely by the landlord due to the absence of individual water meters. It is unlikely that migrants' financial status in Australia explains their continuing commitment to many of the resource-saving practices carried from their home country. However, as we did not cover migrants' financial circumstances in any detail during the interviews, we can only speculate in this regard.

Following on from this, other practices performed in migrants' home countries were rejected or transformed with access to immaterial, abundant and homogenous resources, which redefined understandings of waste and frugality. For example, Dhara's father's water supply was restricted 'big time’ while he lived in Singapore, where Dhara described him as the 'tyrant in the house' when it came to saving water. However, in 
Australia, Dhara's father 'waters like a crazy man', completely ignoring the pleas and threats of his family, and government-imposed water restrictions (introduced in Era 3). Trinh, a second generation Vietnamese migrant, described a similar scenario when explaining her family's efforts to curb the watering practices of her first generation grandfather:

Grandpa used to water everything, the concrete, the garden, he used to water the concrete to cool down the house and so my mum couldn't stop that behaviour from happening. I think he's stopped doing it now but the garden she just couldn't stop, so that was the solution, that we use the [greywater] pipe [from the laundry] (Trinh).

Unlike other migrants’ experiences, old practices can die hard when plentiful supply systems are in easy reach, and 'where the water comes free' (Dhara). Dhara's father and Trinh's grandfather exemplify how immaterial, abundant and homogenous resource systems can create a 'fantasy of endless supply' (Sofoulis 2005), through which links are broken and remade between other practice elements (Pantzar \& Shove 2010) to create new elements (such as an understanding of using and consuming rather than not wasting) and practices (such as watering the pavement)

This era suggests considerable complexity when past elements of practices interact with new ones. Despite resources being provided to householders in one or several homogenous forms (tap water, electricity, gas), many migrant households continued to sort, store and save resources (particularly water) as they had done in their home country, whereas others changed their practices dramatically with the availability and immateriality of resources. Other material elements also became critical in coconstituting practices, such as household appliances and technologies including clothes dryers, air-conditioners, dishwashers and showers. In this sense, knowledge and understandings from Era 1 both remained and receded into the background.

\section{Era 3: Re-materiality, conservation and diversity through innovation}


In the last two decades, energy and water systems in Australia have been characterised by re-materiality, conservation and diversity through innovation, largely triggered by an acute ten year drought (breaking in 2010) leading to water restrictions, conservation targets and/or heightened media attention in every state (Troy 2008). Similarly, recent climate change and peak electricity demand debates have reignited energy concerns (Strengers 2010). As discussed in Section 2, the conservation of resources has been partly recast as a problem of individual responsibility and concern, rather than the responsibility and management of the state (Hobson 2004). Innovation has encouraged diversity in resource supply systems, and is evident in attempts to save, collect and harvest resources; to install and develop Do It Yourself (DIY) systems; and through rebates and incentives to generate power and collect water at the household level (Head \& Muir 2007; Hobson 2006; Maller et al. 2011; Sofoulis et al. 2005), all of which have increased the visibility of these resources in everyday life. Consequently, water use has dropped substantially when compared with Era 2 (Davidson 2008), and residential energy demand has slowed (DEWHA 2008). This is the despite the fact that electricity has been at its most affordable during this era, sitting at around 1.7 per cent of household income for most of the period (although it has begun climbing again in recent years) (AEMC 2011), and water costs are low at 1.2 per cent of household income in 2009-2010 (ABS 2011). However, the characteristics of this era are in tension with Era 2. The resurgence of household conservation and innovation in response to resource concerns has occurred in tandem with attempts to secure supply and protect consumers from resource scarcity as discussed in Section 2.

The data illustrate complexities and overlap between the three eras, as memories of past experiences and interactions with different energies and waters inform current practices. For most of the first and second generation interviewees, the materiality, scarcity and diversity characteristics of the first era resurfaced in response to the similar characteristics of Era 3, particularly in regards to water resources. Migrant householders described how they had responded to the recent drought by producing, capturing and reusing multiple energies and waters as they had done in their home countries. Various 
collection devices installed around the home to catch and reuse water used to shower, launder or cook, reflected pre-existing common understandings and practical knowledge:

I recycle my water, every time I use [it]... I have a sink in the kitchen, and then I use one of those bowls to wash it, and whatever is left I just water the garden (Hannah).

While it is not clear from this study to what extent these practices of collection and reuse are specific to migrants, and to what extent they have occurred more widely in Australian society (and others), our findings are consistent with other studies, which have found a resurgence of generational and cultural practices of collecting and reusing water in response to the drought (Head 2008; Sofoulis et al. 2005).

Importantly, it was not only the heightened media attention and discourse of personal accountability that encouraged migrant householders to respond in the ways they did, but their previous experiences with material, scarce and diverse supply systems:

Conservation was something that we grew up with. [...] It's an element of everyday life. It wasn't a thing that was taught in schools as the way to be (Shanthi).

We hypothesise that migrants were receptive to conservation communication from utilities, government and media, because of these practice memories, which represented a source of adaptive capacity on which they could draw. For example, Hannah discussed her current interest in 'the best way to save the environment' in relation to the scarcity she had experienced as a Vietnamese refugee.

I think because we were having a hard life in the beginning, that's how it brought back the memories how to save whatever. ... Because when we were at the refugee island, we hardly had any fresh water. So why throw it out? Maybe we've been through the hardship in the younger days, 
that's what we learned from. That's what I want to pass all this to the next generation. But not many will listen. (Hannah).

Hannah alludes to a lack of receptivity on the part of the next generation who haven't had direct experience with material, scarce or diverse resource systems. Similarly, first and second generation migrants described all sorts of techniques they used to coerce and punish their second and third generation children, born during the second era of abundant and secure supply, who were variously described as 'terrible' (Lisa), 'self-centred' (Dhara) and excessively wasteful.

[My friend], he goes through two or three showers a day, and he never even does anything [to get dirty] (Reuben).

Through their efforts to control and coerce, Era 1 migrant householders' understandings of waste and conservation slowly pervaded not only their own practices, but also those of their children born in Era 2, despite being counteracted by the fantasy of abundance still embedded in taps and electricity sockets (Sofoulis 2005).

In contrast, householders born during Era 3, specifically during the last decade during which time there has been heightened drought and resource concern in Australia, were as, if not more innovative and conservative as their Era 1 migrant parents:

The younger one, he'll switch ... the TV in the playroom off.... Even if he's got to go to the toilet and come back, he'll switch it off. It's a pain, but I mean I'm not going to stop him (Tessa).

My daughter was born in 2000 so she's known nothing else but drought, with all this rain this year she's like, 'Is this what happens when there's no drought' [...] they're the drought kids. [...] I don't think they'll ever waste water. I think it's been instilled never to waste water (Lisa). 
Not only have these 'drought kids' been born into an era of restriction and scarcity, never experiencing the perceived abundance of modern water provision (Era 2), but practical conservation was a key component of their education, evidenced in programs such as the nationwide Australian Sustainable Schools Initiative (AuSSI):

Yeah, the girls always think to tell me, 'Mummy you should...', 'cause they learn it at school (Tessa).

Despite significant changes experienced by multiple generations during this era, there was concern and resentment that recent decisions to secure water supplies through infrastructure such as desalination would undermine the innovation developed during the drought:

Horrible decision [to build a desalination plant]. I don't know why, I don't know if it's in their guidelines that they have to put it up after a certain level but it's the worst thing they did I think (Tessa).

Householders were concerned that efforts to secure supply and lift water restrictions would represent a return to the supply characteristics of Era 2, and a corresponding return to waste:

They've spent billions of dollars in advertising ... programming us to ... be careful of this ... and now they start to ease.... What happens when it gets eased? ... You think, well why should I save that extra bucket of water? (Marco).

Era 3 therefore points to several generational differences that link the characteristics of energy and water systems to the performance of practices. First and second generation migrants who have experienced materiality, diversity and scarcity in Era 1 draw on this practical history in response to the conservation challenges of Era 3. Second and third 
generation migrants, who have grown up with the immaterial, abundant and homogenous resources of Era 2, require extensive coercion and control from their first and second generation parents to conserve in Era 3. In contrast, third generation migrant children born into Era 3, characterised by re-materiality, conservation and diversity through innovation, have received practical education and are experiencing new forms of materiality that are embodied in their practices. These householders also allude to a possible fourth era in the making, where the characteristics of Era 2 resurface to create immaterial, abundant and homogenous resource systems secured from the risks of climate change.

\section{Towards material, diverse and innovative systems of provision}

In the context of climate change adaptation, where a key aim is to build householders' adaptive capacity and reduce their vulnerability and risk to the impacts of climate change (Smit \& Plifosova 2001), the discussion above raises several important concerns for the policies of supply security. Our analysis suggests that securing supply systems through large-scale infrastructures represents a return to Era 2, or an emerging Era 4, where the characteristics of immateriality, (perceived) abundance and homogeneity inherent in large-scale and centrally-managed systems limit the role of energy and water resources being incorporated as a material element of everyday practices, thereby potentially reducing household conservation and resourcefulness. In contrast, energy and water systems that are materially present, exhibit traits of scarcity, and encourage diversity through innovation, may engage householders as co-managers of their everyday practices (Strengers 2011) — within which 'energies' and 'waters' become an active rather than passive element of everyday routines.

By 'active' we do not mean that energies and waters constantly demand people's attention, but rather that they are actively involved in configuring what makes sense for them to do. This is distinct from educating people about resources and their impacts, or designing devices and feedback programs that constantly keep resource use in people's minds. Instead, we are referring to repositioning energy and water resources as something on which routines and practices depend_as a 'thing' or 'things' (energies and waters), 
rather than an immaterial, homogeneous and abundant supply that magically flows when the bill is paid.

'Resourcefulness', as represented here and implied in the term itself, is not the product of individual attitudes, values or opinions that need be changed and manipulated through behaviour change programs, but rather a trait that emerges and is reproduced from direct experience and familiarity with resources. This finding suggests that resourcefulness comes not only or necessarily through education about how to conserve and use resources wisely, or from financial rewards and penalties, but through experience with making, sorting, treating, coordinating and using energies and waters in the course of everyday practices. The critical insight here is that if policy makers wish to create resourceful (and adaptive or resilient) householders, they need to focus on the characteristics of resource systems and the ways they intersect with everyday practices.

This idea is particularly relevant for water resources, which currently exhibit characteristics of scarcity, being viewed 'as a "precious commodity” needing careful management and conservation in order to protect it for the future' (Kurz et al. 2005, p. 607). Water is regularly materialised in Australians' everyday lives in the form of dam storage levels (often reported as part of TV news bulletins), weather broadcasts, rain, water to drink and to wash with, grey water and so on. Water has also always been considered public property and has resisted processes of commodification on an international scale (Bakker 2005). Consequently, water has been more easily positioned as a co-managed resource than energy, one which both providers and consumers share responsibility and management (Carlsson \& Berkes 2005; Sofoulis \& Strengers 2011). 'Securing' water supplies, through desalination and pipelines, thereby raises serious concerns about the characteristics these systems will exhibit, and their redefined role in co-constituting social practices. Desalination inadvertently repositions water as an immaterial, abundant and homogenous supply system. It will be located where not many can see its impacts, create 'drought-proof' water supplies, and flow from taps indistinguishably from water that comes from dams. The results of our analysis imply a 
declining capacity to adapt and a reduced willingness to respond at the household scale in response to this policy.

In contrast, energy still displays many of the characteristics of Era 2: immateriality, perceived abundance and homogeneity. We cannot see, touch or feel energy; it is apparently always available for a price; and it comes out of the electricity socket in the same form, regardless of how it has been produced. Similarly, Kurz et al. (2005) find that energy is viewed as a 'technology', as ‘infinite’ and as something that we will always be able to produce. Responsibility for this resource is clearly attributed to those who generate and supply it, rather than those who demand it. Unsurprisingly then, it is more difficult to get householders to respond to energy conservation and demand management programs, or to feel responsible for a system that is beyond their control and responsibility, and which does not play an active role in the configuration of practices (Strengers 2011).

In addressing the complex challenges facing both resource sectors, our analysis encourages policy makers to pay further attention to the characteristics of current and future systems of provision, and how they encourage and discourage conservation, shift demand, and develop adaptive and resilient communities, through their integration and intersection with everyday practices. In some ways, these ideas are reflected in recent household trends (and substantial government support) for the purchase and installation of water tanks, grey water systems, solar electricity and solar hot water-all of which potentially materialise energy and water, and provide experience with alternative (distributed) infrastructures. Water tanks and solar panels are now familiar suburban sights and have moved from being novel to normal. Some of the proliferation of distributed systems can be explained by the prolonged drought, particularly true for water but also for energy in terms of an over-abundance of sunshine. Another contributing factor is frustration from some groups within the general public with the perceived lack of government action on climate change and support for alternative infrastructures (One Hundred Percent (100\%) Renewable 2011). However, the critical observation here is that policy making to support the growth of distributed systems has followed rather than led 
the groundswell of interest. Further, despite recent trends towards, and recommendations for, a heterogeneous network of energy and water systems more consistent with the characteristics of Era 3 (Brown et al. 2009; Pears 2007), recent concerns about climate change have pointed policy makers towards centrally managed systems in an attempt to secure supplies as per Era 2 (Brown \& Keath 2008).

\section{Conclusion}

This paper began by suggesting that policies of security are based on illusions that resource supplies can be protected and segmented from demand; that discourses of personal responsibility for climate change impacts can co-exist unproblematically with those of security; and that systems of resource provision can be managed and controlled by one set of actors. Instead, we suggested that systems of resource provision are an important but currently under-theorised element in the constitution of everyday practices, and therefore in the creation of demand. Drawing on theories of social practices, we explored the proposition that energy and water can be thought of as material elements of practices that shape householders' resourcefulness and adaptive capacity.

Focusing on the resource experiences of Australian migrant households spanning several generations and resource eras, we identified specific characteristics of energy and water systems that materialise and immaterialise energy and water in the constitution and performance of everyday practices. Our analysis suggests that the current international policy preoccupation with securing resource supply systems may leave householders less able and willing to adapt to the impacts of climate change. Supply systems characterised by immateriality, perceived abundance and homogeneity may allow resources to recede into the background of everyday life, shift responsibility and control onto governments and private utilities, and lock-in resource intensive ways of life.

Instead, we argued that the resource characteristics of materiality, diversity and scarcity position energies and waters as material elements of everyday practices that represent a currently unacknowledged source of adaptive capacity and resilience. Importantly, we are not suggesting a return to the breakdowns, disruptions, serious hardships and anxiety 
experienced by some of the migrant households in this study before their arrival to Australia. Rather, we conclude that creative, innovative and flexible thinking is needed to replicate certain resource characteristics in modern systems of provision. Encouraging diversification of different energy and water resources for different purposes, incentivising innovation, sharing practical experiences, and ensuring energy and water is physically present in our everyday lives are the beginnings of some practical suggestions for what this might involve.

Theoretically, this paper has explored the idea that energy and water resources can be conceptualised as a 'thing' in the constitution of practices, similar to the role of domestic and digital technologies (Gram-Hanssen 2009; Hand \& Shove 2007; Shove \& Pantzar 2007; Strengers \& Maller 2011), household goods and materials (Maller et al. 2011; Shove et al. 2007) and sporting equipment (Pantzar \& Shove 2010; Shove \& Pantzar 2005). We have suggested that certain characteristics of resource provision systems can create distinct object-like energies and waters-additional non-human actors (Latour 1987) — that contribute to the materiality of practices, and intersect with other elements to reproduce (or limit) resourcefulness. Additionally, we suggested that some system characteristics enable distinct practices of making energy and water, which involve technical ‘equipment’ (donkeys, axes, clay pots etc.), practical knowledge, and understandings to produce specific energies and waters that are integrated into practices that are dependent on them (such as cooking). We conclude that conceptualising resources as a material element of social practices provides useful understandings of how energy and water systems interact with everyday life.

In focusing narrowly on the materiality of infrastructure in migrant household practices, we acknowledge several oversights of this paper. We have deliberately downplayed the role of other practice elements to highlight the role of materiality, particular energy and water, in constituting social practices. We have avoided discussing the practices of policy making, and the various elements involved in making and remaking policies of resources provision and consumer responsibility. More work is required to dissect why policy is made the way it is, what forms of power are involved, and how the practices of policy- 
making could change to account for some of the dynamics highlighted here. Finally, we have not attempted to compare or contrast the practices of migrants with broader societies and populations, for example, those who survived the Great Depression, partly because there are no systematic studies of such groups. We have also avoided important questions about how resources intersect with practices on a wider scale.

Nonetheless, this paper has demonstrated how energy and water systems are intimately intertwined with everyday practices in ways that both limit resource systems' ability to be secured, and potentially undermine the benefits of security. We conclude by calling on researchers and policy makers to expand beyond existing siloes of managing demand or securing supply, by delving into this messy and murky middle ground, where energies and waters are repositioned from passive bystanders to active elements in the constitution of everyday practices. 


\section{References}

ABS 2011, Household expenditure survey, Australia: Summary of Results, 2009-10, Australian Bureau of Statistics (ABS), Canberra.

AEMC 2011, Issues Paper: Power of choice - giving consumers options in the way they use electricity, Australian Energy Market Corporation (AEMC), Sydney, Australia.

Akrich, M 1992, 'The de-scription of technical objects', in WE Bijker \& J Law (eds), Shaping Technology/ Building Society, MIT Press, Cambridge, Mass. [US], pp. 204-24.

Allon, F \& Sofoulis, Z 2006, 'Everyday water: cultures in transition', Australian Geographer, vol. 37, no. 1, pp. 44-55.

Arthur, B 1989, 'Competing technologies, increasing returns, and lock-in by historical events', Economic Journal, vol. 97, pp. 642-65.

Bakker, K 2005, 'Neoliberalizing nature? Market environmentalism in water supply in England and Wales', Annals of the Association of American Geographers, vol. 95, no. 3, pp. 542-65.

Barnett, J \& O'Neill, S 2009, 'Maladaptation', Global Environmental Change.

Bijker, WE, Hughes, T, P \& Pinch, T (eds) 1987, The Social Construction of Technological Systems: New Directions in the Sociology and History of Technology, Massachusetts Institute of Technology, USA.

Brown, R \& Keath, N 2008, 'Drawing on social theory for transitioning to sustainable urban water management: turning the institutional super-tanker', Australian Journal of Water Resources, vol. 12, no. 2, pp. 1-11.

Brown, R, Keath, N \& Wong, T 2009, 'Urban water management in cities: Historical, current and future regimes', Water Science \& Technology, vol. 59, no. 5, pp. 84755.

Carlsson, L \& Berkes, F 2005, 'Co-management: concepts and methodological implications', Journal of Environmental Management, vol. 75, no. 1, pp. 65-76.

CEC 2006, A European Strategy for Sustainable, Competitive and Secure Energy, Commission of the European Communities (CEC), Brussels, Belgium.

Chappells, H \& Shove, E 2004, 'Infrastructures, crises and the orchestration of demand', in D Southerton, B Van Vliet \& H Chappells (eds), Sustainable Consumption: the Implications of Changing Infrastructures of Provision, Edward Elgar, Cheltenham, UK, pp. 130-43.

CoA 2004, Securing Australia's Energy Future, Commonwealth of Australia (CoA), Barton, Australia.

CoA 2011, Securing a clean energy future: The Australian Government's climate change plan, Commonwealth of Australia (CoA), Canberra, Australia.

Davidson, G 2008, 'Down the gurgler: historical influences on Australian domestic water consumption', in P Troy (ed.), Troubled Waters: Confronting the Water Crisis in Australia's Cities, ANU E Press, Canberra, Australia, pp. 37-65.

DEWHA 2008, Energy Use in the Australian Residential Sector 1986-2020, Australian Government: Department of the Environment, Water, Heritage and the Arts (DEWHA), Canberra, Australia.

Dourish, P \& Bell, G 2011, Divining a Digital Future, The MIT Press, Cambridge, Massachusetts. 
DRET 2009, National energy security assessment 2009, Department of Resources Energy and Tourism (DRET), Canberra, Australia.

DRET 2011, Energy: Energy security, Department of Resources, Energy and Tourism (DRET), viewed 13 October 2011, $<$ http://www.ret.gov.au/energy/energy_security/Pages/EnergySecurity.aspx $>$.

DSEWPC 2011, Water for the future, Department of Sustainbility, Environment, Water, Population and Communities (DSEWPC), viewed 7 October 2011, $<$ http://www.environment.gov.au/water/australia/index.html $>$.

Gram-Hanssen, K 2009, 'Standby consumption in households analyzed with a practice theory approach', Research and Analysis, vol. 14, no. 1, pp. 150-65.

Guy, S \& Marvin, S 1996, 'Transforming urban infrastructure provision - the emerging logic of demand side management', Policy Studies, vol. 17, no. 2, pp. 137-47.

Guy, S \& Marvin, S 2001, 'Urban environmental flows: towards a new way of seeing', in S Guy, S Marvin \& T Moss (eds), Urban Infrastructures in Transition: Networks, Buildings, Plans, Earthscan Publications Ltd, London, UK, pp. 22-40.

Ha, T 2007, Greeniology: how to live well, be green and make a difference, Melbourne University Press, Carlton, Victoria.

Hand, M \& Shove, E 2007, 'Condensing practices: ways of living with a freezer', Journal of Consumer Culture, vol. 7, no. 1, pp. 79-104.

Hawkins, G \& Race, K 2011, 'Bottle water practices: reconfiguring drinking in Bangkok households', in R Lane \& A Gorman-Murray (eds), Material geographies of household sustainability, Ashgate, Farnham, UK, pp. 113-24.

Head, L 2008, 'Nature, networks and desire: changing cultures of water in Australia', in P Troy (ed.), Troubled Waters: Confronting the Water Crisis in Australia's Cities, ANU E Press, Canberra, ACT, pp. 67-80.

Head, L \& Muir, P 2007, 'Changing cultures of water in eastern Australian backyard gardens', Social \& Cultural Geography, vol. 8, no. 6, pp. 889-905.

Hobson, K 2004, 'Sustainable consumption in the United Kingdom: the "responsible" consumer and government at "arm's length"', Journal of Environment \& Development, vol. 13, no. 2, pp. 121-39.

Hobson, K 2006, 'Bins, bulbs, and shower timers: on the "techno-ethics' of sustainable living', Ethics, Place and Environment, vol. 9, no. 3, pp. 317-36.

Hughes, T, P 1983, Networks of Power: Electrification in Western Society, Johns Hopkins University Press, Baltimore [USA].

IPCC 2007, Climate change 2007: synthesis report. Summary for policymakers, International Panel on Climate Change (IPCC), Valencia [Spain].

Kurz, T, Donaghue, N, Rapley, M \& Walker, I 2005, 'The ways that people talk about natural resources: discursive strategies as barriers to environmentally sustainable practices', British Journal of Social Psychology, vol. 44, pp. 603-20.

Latour, B 1987, 'Where are the missing masses? The sociology of a few mundane artifacts', in WE Bijker, T Hughes, P \& T Pinch (eds), The Social Construction of Technological Systems: New Directions in the Sociology and History of Technology, Massachusetts Institute of Technology, [USA], pp. 225-58.

Latour, B 2000, 'When things strike back: a possible contribution of 'science studies' to the social sciences', The British Journal of Sociology, vol. 51, no. 1, pp. 107-23. 
Loux, R 2008, Easy green living: the ultimate guide to simple, eco-friendly choices for you and your home, Rodale Inc., New York, USA.

MacKenzie, D \& Wajcman, J 1999, The social shaping of technology, 2nd edn, Open University Press, Buckingham [UK], Philadephia [US].

Maller, C 2011, 'Practices involving energy and water consumption in migrant households', in P Newton (ed.), Urban Consumption, CSIRO Publishing, Collingwood, Australia, pp. 237-50.

Maller, C, Horne, R \& Dalton, T 2011, 'Green rennovations: intersections of daily routines and housing aspirations and narratives of environmental sustainability', Housing, Theory and Society.

One Hundred Percent (100\%) Renewable 2011, 14,000 Conversations: What Australian's are saying about renewable energy, One Hundred Percent (100\%) Renewable, Newtown, NSW.

Otnes, P (ed.) 1988, The Sociology of Consumption, Solum Forlag A/S, Oslo [Norway].

Pantzar, M \& Shove, E 2010, 'Understanding innovation in practice: a discussion of the production and reproduction of Nordic Walking', Technology Analysis \& Strategic Management, vol. 22, no. 4, pp. 447-61.

Pears, A 2007, 'Imagining Australia's energy services futures', Futures, vol. 39, pp. 25371.

Peel, MC, Finlayson, BL \& McMahon, TA 2007, 'Updated world map of the KöppenGeiger climate classification', Hydrology and Earth System Sciences, vol. 11, no. 5, pp. 1633-44.

Reckwitz, A 2002a, 'The status of the 'material' in theories of culture. From 'social structure' to 'artefacts", Journal for the Theory of Social Behaviour, vol. 32, no. 2, pp. 195-217.

Reckwitz, A 2002b, 'Toward a theory of social practices: a development in culturalist theorizing', Journal of Social Theory, vol. 5, no. 2, pp. 243-63.

Schatzki, TR 2001, 'Practice theory', in TR Schatzki, K Knorr Cetina \& E Von Savigny (eds), The Practice Turn in Contemporary Theory, Routledge, New York, USA.

Schatzki, TR 2002, The Site of the Social: a Philosophical Account of the Constitution of Social Life and Change, The Pennsylvania State University Press, Pennsylvania, USA.

Shove, E 2010, 'Social Theory and Climate Change: Questions Often, Sometimes and Not Yet Asked', Theory, Culture \& Society, vol. 27, no. 2-3, pp. 277-88.

Shove, E \& Chappells, H 2001, 'Ordinary consumption and extraordinary relationships: utilities and their users', in J Gronow \& A Warde (eds), Ordinary Consumption, Routledge, London, UK, pp. 45-58.

Shove, E \& Pantzar, M 2005, 'Consumers, producers and practices: understanding the invention and reinvention of Nordic walking', Journal of Consumer Culture, vol. 5, no. 1, pp. 43-64.

Shove, E \& Pantzar, M 2007, 'Recruitment and reproduction: the carriers of digital photography and floorball', Human Affairs, vol. 17, pp. 154-67.

Shove, E, Watson, M, Hand, M \& Ingram, J 2007, The Design of Everyday Life, Berg, Oxford [UK].

Smit, B \& Plifosova, O 2001, 'Adaptation to climate change in the context of sustainable development and equity', in JJ McCarthy, OF Canziani, NA Leary, DJ Dokken \& 
KS White (eds), Climate Change 2001: Impacts, Adaptation and Vulnerability, Cambridge University Press, Cambridge, pp. 879-912.

Sofoulis, Z 2005, 'Big water, everyday water: a sociotechnical perspective', Continuum: Journal of Media \& Cultural Studies, vol. 19, no. 4, pp. 445-63.

Sofoulis, Z, Allon, F, Campbell, M, Attwater, R \& Velayutham, S 2005, Everyday Water: Values, Practices, Interactions: a UWS Research Partnerships Project: Final Report, University of Western Sydney presented to Delfin Lend Lease, Sydney, NSW.

Sofoulis, Z \& Strengers, Y 2011, 'Healthy engagement: evaluating models of providers and users for cities of the future', paper presented to Australia's National Water Conference and Exhibition (Ozwater) 2011, Adelaide, Australia, 8-10 May.

Southerton, D, Chappells, H \& Van Vliet, B (eds) 2004, Sustainable Consumption: the Implications of Changing Infrastructures of Provision, Edward Elgar, Cheltenham, UK.

Spearritt, P 2008, 'The water crisis in Southeast Queensland: how desalination turned the region into carbon emission heaven', in P Troy (ed.), Troubled Waters:

Confronting the Water Crisis in Australia's Cities, ANU E Press, Canberra, ACT, pp. 19-36.

Star, SL 1999, 'The Ethnography of Infrastructure', American Behavioral Scientist, vol. 43, no. 3, pp. 377-91.

Strengers, Y 2009, 'Bridging the divide between resource management and everyday life: smart metering, comfort and cleanliness', PhD Thesis, RMIT University.

Strengers, Y 2010, 'Air-conditioning Australian households: a trial of Dynamic Peak Pricing', Energy Policy, vol. 38, no. 11, pp. 7312-22.

Strengers, Y 2011, 'Beyond demand management: co-managing energy and water consumption in Australian households', Policy Studies, vol. 32, no. 1, pp. 35-58.

Strengers, Y \& Maller, C 2011, 'Integrating health, housing and energy policies: the social practices of cooling', Building Research \& Information, vol. 39, no. 2, pp. 154-68.

Summerton, J (ed.) 1994, Changing Large Technical Systems, Westview Press Inc., Colorado [USA].

Trask, C 2006, It's easy being green: a handbook for earth-friendly living, Gibbs Smith, Layton, Utah, USA.

Troy, P 2008, 'Introduction: the water services problem', in P Troy (ed.), Troubled Waters: Confronting the Water Crisis in Australia's Cities, ANU E Press, Canberra, ACT.

Van Vliet, B, Chappells, H \& Shove, E 2005, Infrastructures of Consumption: Environmental Innovation in the Utilities Industries, Earthscan, London, UK.

Winner, L 1986, The Whale and the Reactor: a search for limits in an age of high technology, The University of Chicago Press, Chicago [USA].

Winstone, R, Bolton, P \& Gore, D 2007, Energy Security, House of Commons, London, UK.

Wong, P 2009, '\$16 million towards securing Broken Hill's water supply', viewed 7 October 2011, $<$ http://www.climatechange.gov.au/minister/previous/wong/2009/mediareleases/March/mr20090304c.aspx>. 
Woodruff, A, Hasbrouck, J \& Augustin, S 2008, 'A bright green perspective on sustainable choices', paper presented to CHI 2008, Florence, Italy, 5-10 April.

\section{Endnotes}

